\title{
Aromatase: a neuroprotective enzyme
}

\author{
Luis M. Garcia-Segura ${ }^{a, *}$, Sergio Veiga ${ }^{\text {a,b }}{ }^{\text {, Amanda Sierra }}{ }^{\text {a }}$, \\ Roberto C. Melcangi ${ }^{\mathrm{b}}$, Iñigo Azcoitia ${ }^{\mathrm{c}}$ \\ ${ }^{a}$ Instituto Cajal, Consejo Superior de Investigaciones Cientificas (CSIC), Avenida Doctor Arce 37, E-28002 Madrid, Spain \\ ${ }^{\mathrm{b}}$ Department of Endocrinology and Center of Excellence on Neurodegenerative Diseases, University of Milan, I-20133 Milan, Italy \\ ${ }^{\mathrm{c}}$ Departamento de Biología Celular, Facultad de Biología, Universidad Complutense, E-28040 Madrid, Spain
}

Received 29 May 2003; accepted 10 September 2003

\begin{abstract}
Estradiol, in addition to its participation in neuroendocrine regulation and sexual behavior, has neuroprotective properties. Different types of brain injury induce the expression of the enzyme aromatase in reactive astroglia. This enzyme catalyzes the conversion of testosterone and other $\mathrm{C} 19$ steroids to estradiol. Genetic or pharmacological inhibition of brain aromatase results in marked neurodegeneration after different forms of mild neurodegenerative stimuli that do not compromise neuronal survival under control conditions. Furthermore, aromatase mediates neuroprotective effects of precursors of estradiol such as pregnenolone, dehydroepiandrosterone (DHEA) and testosterone. These findings strongly suggest that local formation of estradiol in the brain is neuroprotective and that the induction of aromatase and the consecutive increase in the local production of estradiol are part of the program triggered by the neural tissue to cope with neurodegenerative insults. Aromatase may thus represent an important pharmacological target for therapies conducted to prevent aging-associated neurodegenerative disorders.
\end{abstract}

(C) 2003 Elsevier Ltd. All rights reserved.

\section{Contents}

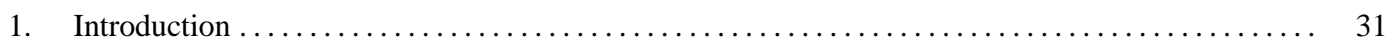

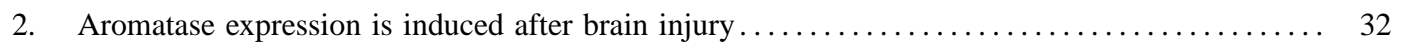

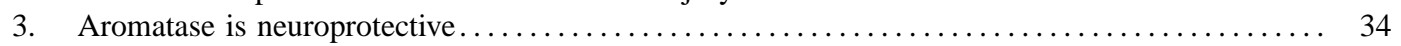

3.1. Aromatase-deficient mice are more susceptible to neurodegeneration in the hippocampus 34

3.2. Systemic aromatase inhibition enhances neurodegeneration in the hippocampus ........ 34

3.3. Aromatase is neuroprotective in a model of cerebellar ataxia ................... 34

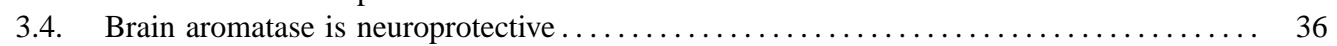

3.5. Estradiol synthesis mediates neuroprotection by aromatase $\ldots \ldots \ldots \ldots \ldots \ldots \ldots \ldots \ldots$

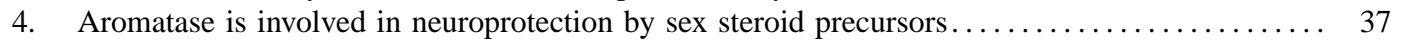

4.1. Neuroprotection by testosterone is abolished by aromatase inhibition ............. 37

4.2. Neuroprotection by sex steroid precursors is abolished by aromatase inhibition ....... 37

5. Is the brain or the periphery the source of substrates for brain aromatase? ........... 38

6. Therapeutic perspectives: neuroprotection and brain aging $\ldots \ldots \ldots \ldots \ldots \ldots \ldots \ldots \ldots \ldots \ldots$

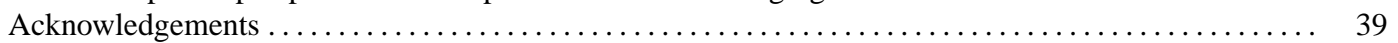

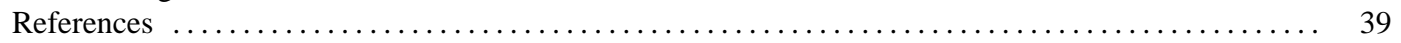

Abbreviations: 3AP, 3-acetylpirydine; ArKO, aromatase knock-out; DHEA, dehydroepiandrsoterone; DHT, dihydrotestosterone; HRT, hormonal replacement therapy; NADPH, reduced nicotinamide adenine dinucleotide phosphate

* Corresponding author. Tel.: +34-9-1585-4729; fax: +34-9-1585-4754.

E-mail address: lmgs@cajal.csic.es (L.M. Garcia-Segura).

\section{Introduction}

Decreased levels of estrogen after menopause are associated with loss of cognitive skills, the progression of neurodegenerative disorders, increased depressive symptoms, and other psychological disturbances in women (Fillit, 1994; Paganini-Hill, 1995; Paganini-Hill and Henderson, 1996; Yaffe et al., 1998; Saunders-Pullman et al., 1999; 
Sherwin, 1999; Wolf et al., 1999). Therefore, it has been proposed that estrogen replacement therapies may ameliorate the loss of brain function with aging (Costa et al., 1999; Hogervorst et al., 2000; Resnick and Maki, 2001; Tsang et al., 2000). This proposition is supported by substantial evidence from animal studies indicating that estradiol replacement is neuroprotective in both sexes (for recent reviews, see Chowen et al., 2000; Garcia-Segura et al., 2001; Green and Simpkins, 2000; Lee and McEwen, 2001; Wise et al., 2001). Neuroprotective properties have also been ascribed to estradiol precursors such as pregnenolone (3ß-hydroxy-5-pregnen-20-one), dehydroepiandrosterone (DHEA, 3 $\alpha$-hydroxy-5-androstene-17-one) and testosterone. However, the results of several studies in humans have shown that hormonal replacement therapy (HRT) with estradiol and progesterone has no positive effect for neurodegenerative diseases or stroke and even may have a negative impact on cognition in postmenopausal women with Alzheimer's disease (Shaywitz and Shaywitz, 2000; Fillit, 2002; Azcoitia et al., 2003a; Wise, 2003). Therefore, it is necessary to establish alternatives to HRT. One possibility is to increase local estrogen synthesis in the brain and not in other organs, to avoid health risks associated to peripheral actions of estradiol and to avoid the potential negative effects of progestagens in the brain. However, the potential neuroprotective role of endogenous estradiol formation has been largely neglected.

Testosterone and other $\mathrm{C} 19$ steroids are converted to estradiol by aromatase (Fig. 1), an enzyme that consists of two components: a cytochrome P450 (P450 aro), the product of the cyp19 gene, and the ubiquitous flavoprotein NADPH (reduced nicotinamide adenine dinucleotide phosphate)-cytochrome P450 reductase (Simpson and Davis, 2001; Kamat et al., 2002). Aromatase is expressed in the brain (Naftolin et al., 1971), where it is involved in the regulatory effects of androgens, via conversion to estrogens, on neural differentiation, neural plasticity, neuroendocrine function and sexual behavior (MacLusky and Naftolin, 1981; Hutchison, 1991; Lephart, 1996). In this study we review evidence indicating that local estradiol formation by aromatase participates in the endogenous mechanisms used by the brain to cope with neurodegeneration.

\section{Aromatase expression is induced after brain injury}

In teleost fishes aromatase is expressed in neurons (Gelinas and Callard, 1997) as well as in radial glia (Forlano et al., 2001; Menuet et al., 2003), under normal conditions. Furthermore, aromatase is expressed in both neuronal and glial cells in primary cultures of developing zebra finch telencephalon (Schlinger et al., 1994, 1995). In contrast, aromatase is expressed exclusively by neurons under normal conditions in the central nervous system of mammals (Negri-Cesi et al., 1992; Naftolin, 1994; Lephart, 1996; Balthazart and Ball, 1998). These neurons are mainly localized in the lateral septal region, the bed nucleus of the stria terminalis, the amygdala, several hypothalamic nuclei, the medial preoptic area, the nucleus accumbens and several regions of the cortex, especially in the piriform lobe (Balthazart et al., 1991; Jakab et al., 1993, 1994; Foidart et al., 1995). Aromatase immunoreactivity has not been observed in glial cells in the rodent brain in vivo under normal

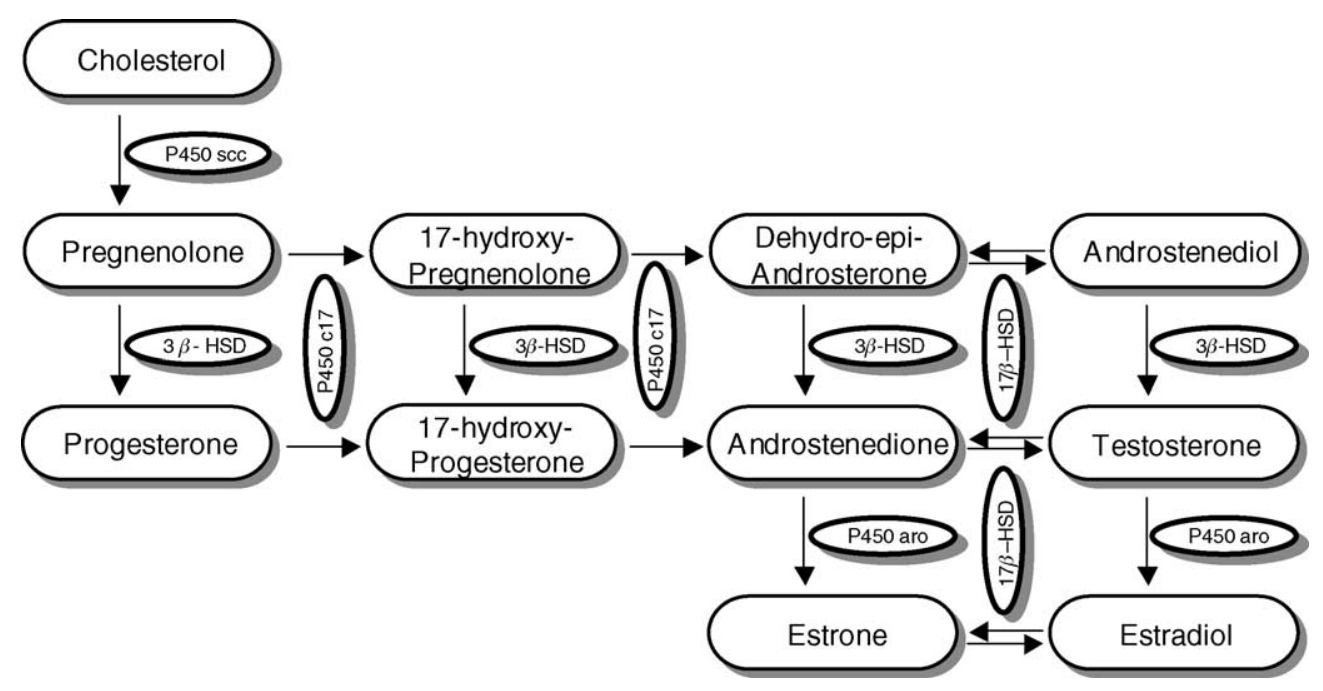

Fig. 1. Estradiol biosynthesis in the central nervous system. Cholesterol is converted to pregnenolone, catalyzed by the cytochrome P450 side-chain cleavage (P450 scc). Pregnenolone is then converted to progesterone, catalyzed by the $3 \beta$-hydroxy-steroid dehydrogenase (3 $\beta$-HSD). Pregnenolone and progesterone can be further converted, via 17-hydroxy-pregnenolone and 17-hydroxy-progesterone, respectively, to dehydroepiandrosterone and androstenedione. These conversions are catalyzed by the $17 \alpha$-hydroxylase/C17-20-lyase (P450 c17). Then, the 17 $\beta$-hydroxylase/C17-20-lyase (17 $\beta$-HSD) catalyzes the conversion of DHEA in androstenediol and the conversion of androstenedione in testosterone. Androstenediol is converted to testosterone by the $3 \beta$-HSD. Androstenedione and testosterone can be converted to estrone and estradiol, respectively, by aromatase (P450 aro). 
circumstances. However, rodent astrocytes isolated from the cerebral cortex of neonatal rats express aromatase (Zwain et al., 1997; Zwain and Yen, 1999a). It is possible that specific culture conditions may induce aromatase expression in astrocytes. Indeed, recent results (Azcoitia et al., 2003b) indicate that stressful conditions, such as serum deprivation, induce aromatase expression in cultured astrocytes. Furthermore, different forms of neurotoxic and mechanical lesions in the brains of rats and mice increase aromatase activity and induce de novo expression of the enzyme in reactive glia (Garcia-Segura et al., 1999a,b). The morphology and ultrastructure of aromatase-immunoreactive glial cells, together with the co-expression of the astroglial marker GFAP, indicate that most, if not all, aromatase-expressing glial cells are astrocytes (Fig. 2). The induction of aromatase expression in astrocytes after a brain lesion was accompanied by a significant increase in aromatase enzymatic activity. Aromatase-expressing astrocytes are observed in both sexes and in all injured brain areas, including the cortex, corpus callosum, striatum, hippocampus, thalamus and hypothalamus (Garcia-Segura et al., 1999a,b). This indicates that astrocytes from most brain areas have the potential for expressing aromatase, and therefore to produce estradiol, in response to injury. Furthermore, Peterson et al. (2001) have shown that in the zebra finch brain aromatase mRNA and protein are rapidly and locally upregulated in glia following neural injury. This finding suggests that injury-dependent upregulation of aromatase may be a conserved characteristic of the vertebrate brain and an important component of the initial response of neural tissue to injury (Peterson et al., 2001).

The increased expression of aromatase in injured brain areas (Garcia-Segura et al., 1999a,b; Peterson et al., 2001) suggests that this enzyme may be involved in the protection of nervous tissue by increasing local estrogen levels. Estrogen formed by astrocytes may be released as a trophic factor

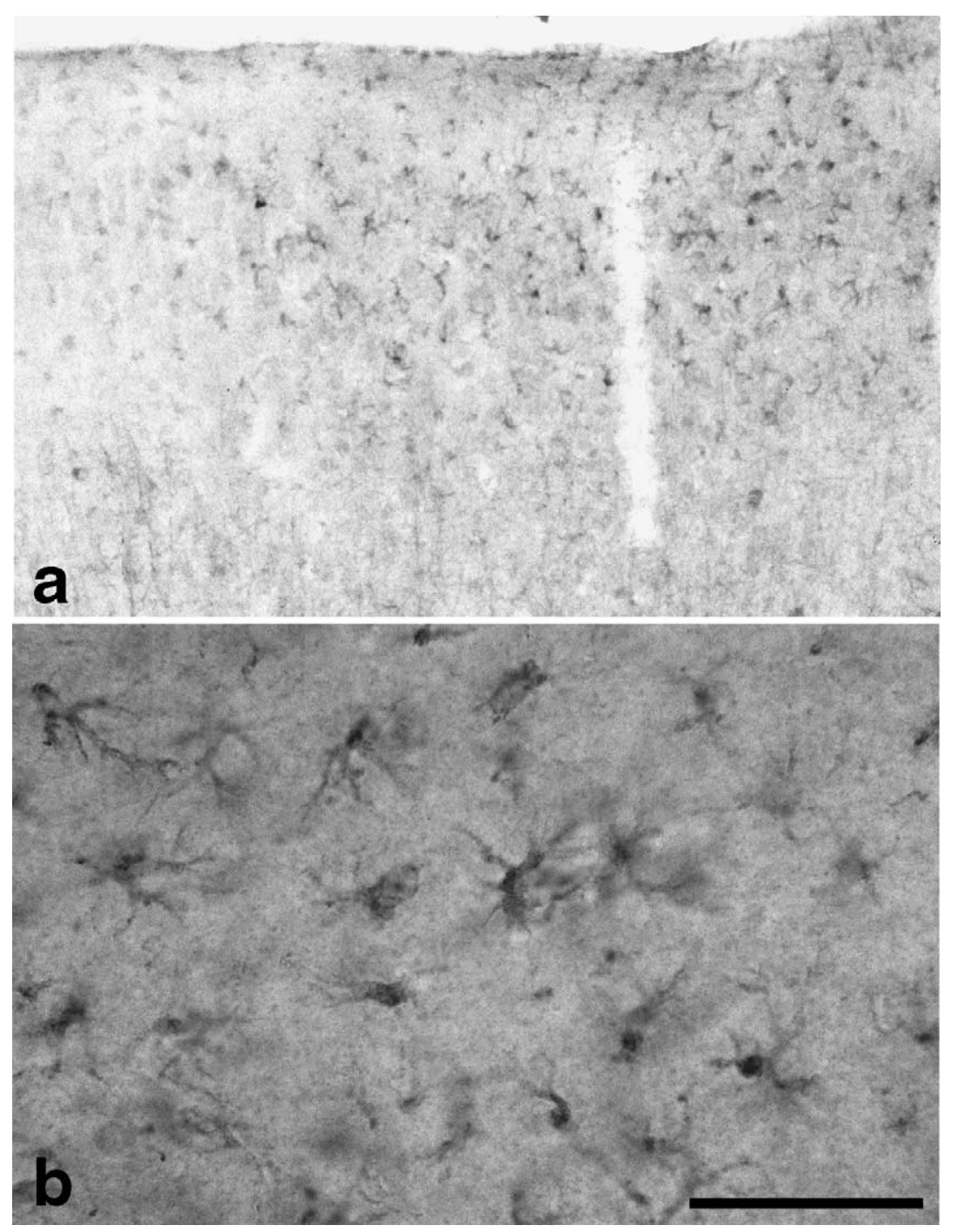

Fig. 2. Induction of aromatase in the cerebral cortex of a male mouse after a cryogenic lesion: (a) low magnification showing aromatase immunoreactivity in the injured cortex; (b) high magnification showing that aromatase immunoreactivity is present in reactive astrocytes. Scale bar: (a) $500 \mu \mathrm{m}$; (b) $50 \mu \mathrm{m}$. 
for damaged neurons and be involved in the compensatory restructuring of injured brain tissue. Thus, estrogen released by astroglia may affect synaptic function, selective regeneration of neuronal processes and local cerebral blood flow, contributing to facilitation of neuronal recovery and reduction of neuronal death.

\section{Aromatase is neuroprotective}

\subsection{Aromatase-deficient mice are more susceptible to neurodegeneration in the hippocampus}

Systemic administration of domoic acid in mice results in neurodegenerative damage in the hippocampal formation (Strain and Tasker, 1991). The neurodegenerative effects of domoic acid are mediated by an increase in intracellular calcium, as well as by an increased release of glutamate that results in the activation of NMDA receptors (Berman and Murray, 1997; Nijjar and Nijjar, 2000). The administration of domoic acid has been used to assess the effect of aromatase deficiency in neurodegeneration (Fig. 3). Aromatase knock-out (ArKO) male mice and their wild type male littermates were injected with a low dose of domoic acid that does not induce neurodegeneration in the hippocampus of normal mice. The number of neurons was then assessed in the hilus of the dentate gyrus using unbiased morphometric techniques (Azcoitia et al., 2001). The number of hilar neurons was not significantly different between ArKO mice and their wild type littermates, indicating that aromatase deficiency does not affect the development and survival of hilar neurons, at least in young adult animals. However, the number of hilar neurons in ArKO mice injected with domoic acid was significantly decreased compared to control ArKO mice, to wild type controls and to wild type mice injected with domoic acid (Azcoitia et al., 2001). This finding indi- cates that aromatase deficiency increases the vulnerability of hilar neurons to neurotoxic degeneration.

\subsection{Systemic aromatase inhibition enhances neurodegeneration in the hippocampus}

A further proof of the neuroprotective role of aromatase has been obtained in intact male rats that were implanted with an osmotic minipump containing the aromatase inhibitor fadrozole (Azcoitia et al., 2001). Kainic acid, a well-characterized neurotoxin for hilar neurons in the rat (Buckmaster and Dudek, 1997), was administered at a low dose that does not affect hilar neurons in intact male rats, but results in significant neuronal loss in the hilus of castrated rats (Azcoitia et al., 1999a). As expected, the number of hilar neurons was not affected by kainic acid in control animals that were not treated with fadrozole. Furthermore, fadrozole alone did not affect the number of hilar neurons, indicating that fadrozole is not neurotoxic by itself. However, animals that were treated with both fadrozole and kainic acid had a significant decrease in the number of hilar neurons compared to animals treated with vehicle, to animals treated with kainic acid alone and to animals treated with fadrozole alone (Azcoitia et al., 2001). The loss of hilar neurons was accompanied by an increase in the number of neurons stained with Fluoro-Jade, a marker of dying cells (Schmued et al., 1997) (Fig. 4). These findings further support the results obtained with the ArKO mice and confirm that aromatase is neuroprotective against excitotoxicity.

\subsection{Aromatase is neuroprotective in a model of cerebellar ataxia}

The neuroprotective effect of aromatase has been also assessed in a model of cerebellar ataxia produced by the degeneration of rat inferior olivary nucleus after treatment with

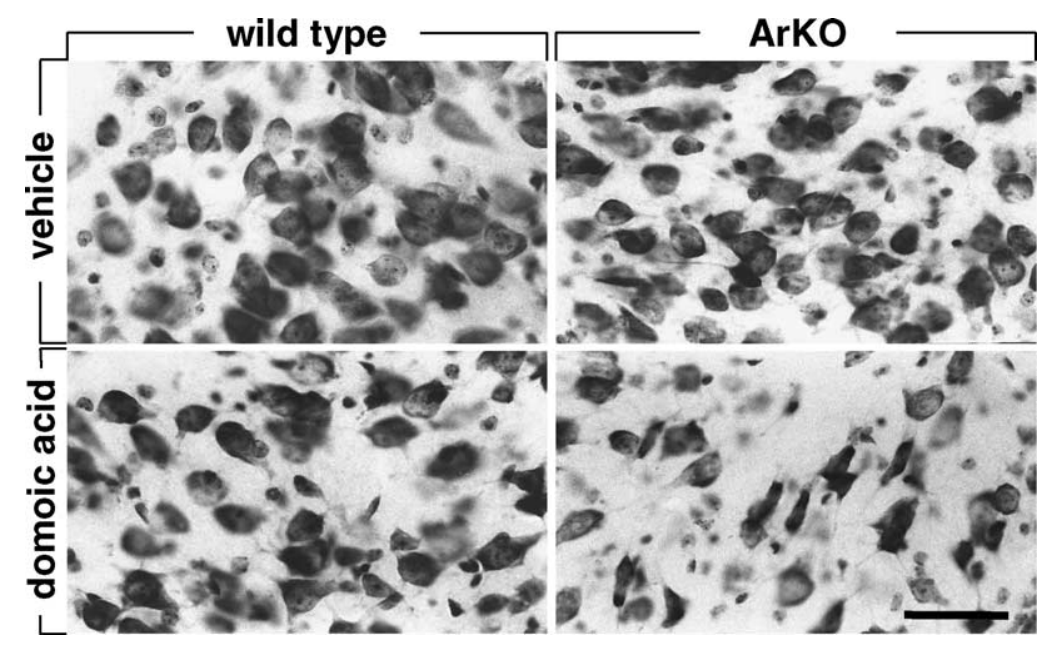

Fig. 3. Nissl-stained neurons in the hilus of the dentate gyrus of aromatase knock-out (ArKO) and wild type male mice injected with vehicle or with a low dose of the neurotoxic domoic acid (i.p., $0.5 \mathrm{mg} / \mathrm{kg}$ bw). The low dose of domoic acid did not affect hilar neurons in wild type mice but caused a significant neuronal loss in the aromatase-deficient mice. Scale bar: $50 \mu \mathrm{m}$. 


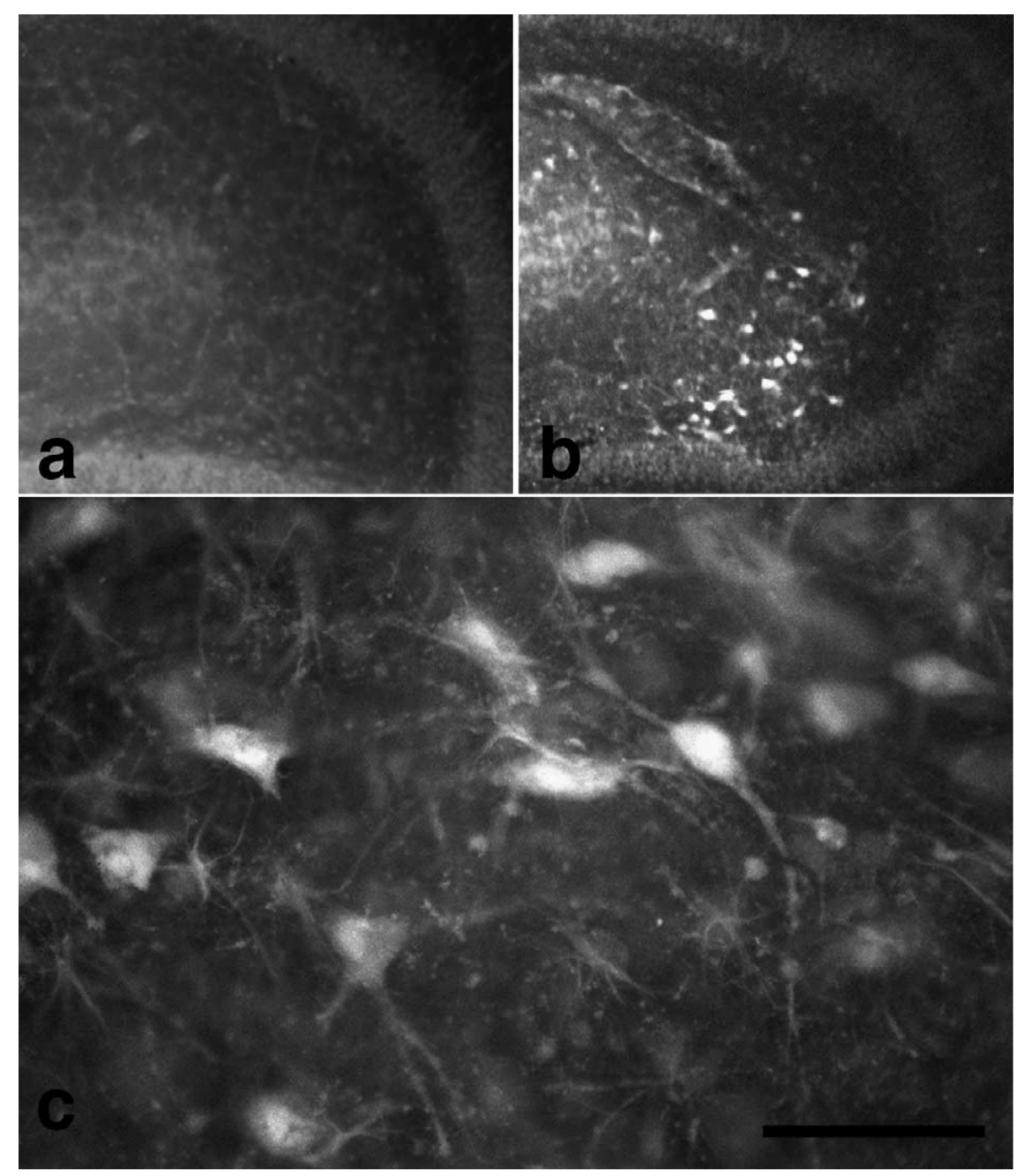

Fig. 4. Hilus of the dentate gyrus of male Wistar albino rats treated with: (a) vehicle; or (b) the aromatase inhibitor fadrozole $(4.16 \mathrm{mg} / \mathrm{ml})$ and injected with a low dose of the neurotoxic kainic acid (i.p., $7 \mathrm{mg} / \mathrm{kg}$ bw). The low dose of kainic acid did not affect hilar neurons in rats treated with vehicle, but increases labeling with Fluoro-Jade, a marker of dying cells, in rats treated with the aromatase inhibitor. (c) High magnification of the hilus of the dentate gyrus of a rat treated with fadrozole and kainic acid showing Fluoro-Jade stained neurons. Scale bar: (a and b) $500 \mu \mathrm{m}$; (c) $50 \mu \mathrm{m}$.

3-acetylpirydine (3AP), an antimetabolite of nicotinamide. Olivary neurons have a very high metabolic rate and are, therefore, very sensitive to $3 \mathrm{AP}$ toxicity. The destruction of the inferior olive results in loss of climbing fiber input to cerebellar Purkinje neurons (Baetens et al., 1982), and this deafferentiation leads to ataxia (Fernandez et al., 1999).

Inferior olivary neurons express aromatase (Sierra et al., 2003a) and estrogen receptors (Shughrue et al., 1997), and their activity is affected by estradiol (Smith, 1998). The action of estradiol in this nucleus may be important for the maintenance of motor function that is under the control of olivo-cerebellar system. Indeed, postmenopausal women receiving estrogens have a decreased risk of falling and better postural balance than non-estrogen users (Naessen et al., 1997; Randell et al., 2001).

The effect of estradiol administration on the survival of inferior olivary neurons was assessed in male rats treated with 3AP (Sierra et al., 2003a). Animals were castrated to reduce plasma testosterone levels and, therefore, to reduce the formation of estradiol from its circulating precursor. Immediately after castration, animals were implanted with a silicone tube that was either empty or filled with estradiol. One week later, animals were injected with 3AP. The toxicity of 3AP was qualitatively assessed by Nissl-staining and by a semi-quantitative analysis of neurons stained with Fluoro-Jade, a marker of dying cells (Schmued et al., 1997). Furthermore, the number of surviving inferior olivary neurons was assessed by unbiased morphometry using NeuN, a specific neuronal marker (Mullen et al., 1992). Administration of 3AP resulted in a significant loss of NeuN immunoreactive neurons in the inferior olivary nucleus. The neuronal loss was prevented by estradiol treatment. Furthermore, estradiol decreased the number of Fluoro-Jade stained cells in the inferior olive (Sierra et al., 2003a). In 


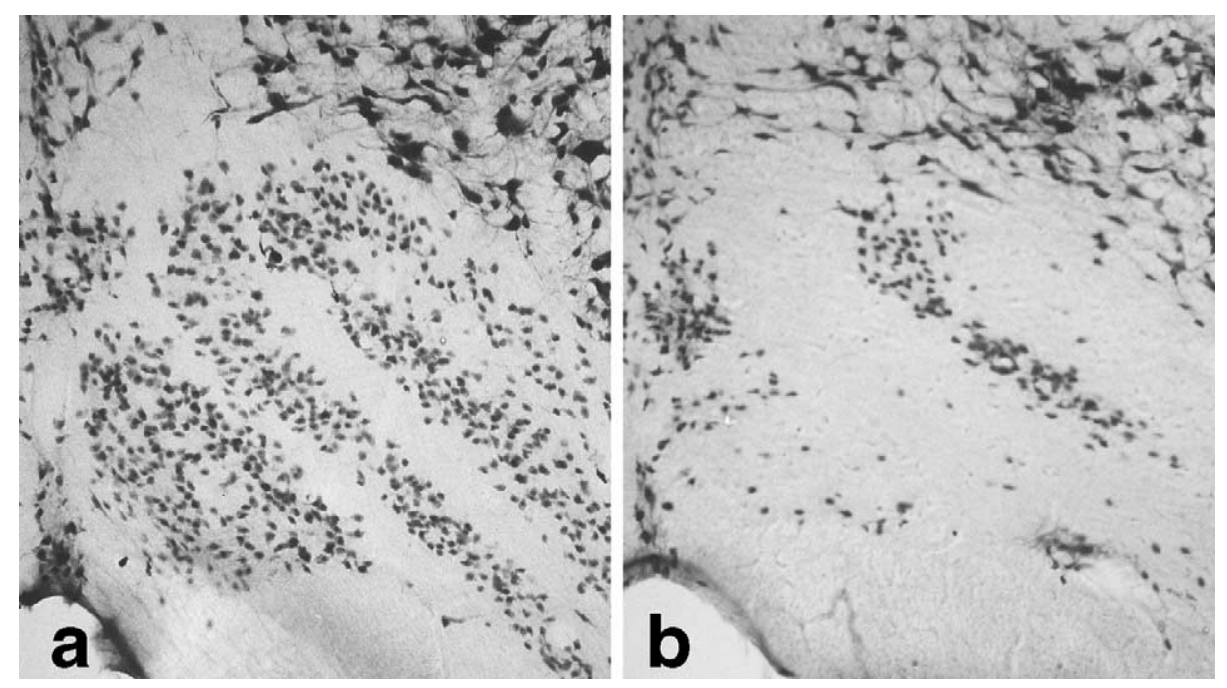

Fig. 5. Inferior olivary nucleus from male rats treated with: (a) vehicle; or (b) the aromatase inhibitor fadrozole (4.16 mg/ml) and the neurotoxic 3-acetylpirydine (3AP: $30 \mathrm{mg} / \mathrm{kg}$ ). $3 \mathrm{AP}$ did not affect inferior olivary neurons in the rats treated with vehicle, but resulted in a massive neuronal loss in the rats treated with the aromatase inhibitor.

conclusion, estradiol administration to castrated males resulted in a significant protection of inferior olivary neurons against $3 \mathrm{AP}$.

Having determined that exogenous estradiol was neuroprotective for inferior olivary neurons, the next question was to determine whether endogenous estradiol formation was neuroprotective as well. The inhibition of aromatase with fadrozole enhanced the injury produced by $3 \mathrm{AP}$ in the inferior olive of intact male rats (Fig. 5). Fadrozole treatment decreased the number of NeuN-expressing neurons that survived to 3AP and increased the number of Fluoro-Jade stained dying cells (Sierra et al., 2003a). Therefore, aromatase is neuroprotective for inferior olivary neurons.

\subsection{Brain aromatase is neuroprotective}

The studies mentioned above, on ArKO mice and on rats after systemic administration of the aromatase inhibitor fadrozole, indicate that aromatase is neuroprotective. However, these studies did not differentiate between brain aromatase and the peripheral enzyme. To test the role of local brain aromatase activity in neuroprotection, the aromatase inhibitor fadrozole was infused into the right lateral cerebral ventricle of a group of male rats (Azcoitia et al., 2001). Fadrozole was administered at a concentration within the range previously shown to inhibit aromatase in the rat brain (Bonsall et al., 1992; Clancy et al., 1995; Vagell and McGinnis, 1997). The number of hilar neurons in the left hippocampal formation was assessed after an injection of a low dose of kainic acid that does not induce neurodegeneration in intact males. Indeed, the number of hilar neurons was not affected by this low dose of kainic acid in control animals. Furthermore, the infusion of fadrozole in the cerebral ventricle did not affect the number of hilar neurons in control animals. This is a further indication that aromatase activity is not indispensable to maintain hilar neuron survival under normal circumstances. However, animals that were treated with both fadrozole and kainic acid showed a significant decrease in the number of hilar neurons compared to animals treated with vehicle, to animals treated with kainic acid alone and to animals treated with fadrozole alone (Azcoitia et al., 2001). This finding indicates that brain aromatase is neuroprotective.

\subsection{Estradiol synthesis mediates neuroprotection by aromatase}

To determine whether the formation of estradiol is involved in the neuroprotective effect of aromatase, male rats were treated with fadrozole, kainic acid and estradiol. Estradiol treatment prevented the neurodegenerative effect of kainic acid in animals treated with fadrozole. The number of hilar neurons in animals treated with fadrozole, kainic acid and estradiol was not significantly different from control animals and was significantly higher than in animals treated with fadrozole and kainic acid (Azcoitia et al., 2001). This finding, showing that the neurodegenerative effect of aromatase deficiency is counterbalanced by the aromatase product estradiol, strongly suggests that the neuroprotective properties of aromatase lies in its ability to catalyze the formation of estradiol rather than reducing testosterone levels.

A similar conclusion has been obtained in the inferior olivary nucleus (Sierra et al., 2003a). The neuronal loss induced by the aromatase inhibitor fadrozole in the inferior olivary nucleus of male rats treated with the neurotoxic 3AP is reverted by estradiol (Sierra et al., 2003a). This indicates that the toxic effect of fadrozole is due to the inhibition of aromatase and not to another unknown effect of the drug. Therefore, we may conclude that estradiol formation also mediates the neuroprotective effect of aromatase in this model. 


\section{Aromatase is involved in neuroprotection by sex steroid precursors}

\subsection{Neuroprotection by testosterone is abolished by aromatase inhibition}

Recent studies have shown that the hippocampal hilar neurons of castrated male mice are more sensitive to domoic acid-induced degeneration than the hilar neurons from intact males (Azcoitia et al., 2001). This was observed using a low dose of domoic acid that does not affect hilar neurons in intact animals. However, the same low dose of domoic acid is able to induce significant neuronal loss in mice with reduced androgen levels as a result of castration, indicating that physiological levels of testicular secretions are neuroprotective. Furthermore, testosterone replacement prevents domoic acid-induced neuronal loss, indicating that this estradiol precursor and substrate of aromatase protects hilar neurons from neurotoxic insults in vivo. Testosterone promotes neuroprotection in other experimental models as well. The hormone promotes the survival of specific neuronal populations (Yu, 1982; Jones, 1994; Perez and Kelly, 1996; Rasika et al., 1999), induces motor axon regeneration in axotomized motoneurons (Yu, 1982; Jones, 1994; Perez and Kelly, 1996), prevents the hyperphosphorylation of the microtubule-associated protein tau (Papasozomenos, 1997), which is abnormally hyperphosphorylated in Alzheimer's disease, reduces neuronal secretion of $\beta$-amyloid peptides associated with Alzheimer's disease (Gouras et al., 2000 ), attenuates $\beta$-amyloid toxicity (Pike, 2001), protects granule neurons of the dentate gyrus from adrenalectomy (Frye and McCormick, 2000) and decreases apolipoprotein E4-induced cognitive deficits (Raber et al., 2002). Part of the neuroprotective properties of testosterone may be the result of the activation of androgen receptors (Ahlbom et al., 2001; Hammond et al., 2001). However, in the case of protection of hilar neurons against domoic acid, dihydrotestosterone (DHT), a $5 \alpha$-reduced metabolite of testosterone that acts on androgen receptors, is not protective (Azcoitia et al., 2001). Interestingly, DHT is not 'aromatizable' to estradiol. This suggests that the neuroprotective effect of testosterone in this experimental model may be due, at least in part, to its conversion to estradiol by the enzyme aromatase.

To directly assess whether the neuroprotective effect of testosterone depends on its aromatization to estradiol, castrated male rats were treated with kainic acid in the presence or absence of the aromatase inhibitor fadrozole (Azcoitia et al., 2001). Animals were treated with a dose of kainic acid that causes neurodegeneration in the hilus of the dentate gyrus (Azcoitia et al., 1999a). Kainic acid resulted in significant neuronal loss in the hilus of castrated male rats compared to animals treated with vehicles. Testosterone administration prevented the neurodegenerative effect of kainic acid, confirming the finding obtained in mice. However, fadrozole prevented neuroprotection by testosterone, suggesting that testosterone exerts neuroprotective effects in this experimental model via conversion to estradiol (Azcoitia et al., 2001). This finding gives additional support to the idea that aromatase plays a role in neuroprotection by promoting the formation of estradiol (see Section 3.5).

\subsection{Neuroprotection by sex steroid precursors is abolished by aromatase inhibition}

The sex steroid precursors pregnenolone and DHEA have neuroprotective properties. Pregnenolone reduces neuronal death in brain cell cultures (Bologa et al., 1987) and protects mouse hippocampal HT-22 cells against glutamate and amyloid-beta protein toxicity (Gursoy et al., 2001). In vivo, pregnenolone protects hippocampal neurons from kainic acid toxicity (Veiga et al., 2003). Furthermore, pregnenolone and its sulfate derivative enhance memory and cognitive function in different animal models (Flood et al., 1992; Vallée et al., 1997, 2001; Darnaudery et al., 2002) and increase neurogenesis in the adult rat hippocampus (Mayo et al., 2001). DHEA has been shown to protect cells of the clonal mouse hippocampal cell line HT-22 against the excitatory amino acid glutamate (Cardounel et al., 1999), as well as primary hippocampal cultured neurons against the neurotoxic actions of AMPA and kainic acid (Kimonides et al., 1998). In vivo, DHEA protects hippocampal pyramidal neurons against unilateral infusions of NMDA (Kimonides et al., 1998) or systemic administration of kainic acid (Veiga et al., 2003). DHEA and its sulfate derivative have been shown to protect neurons from other degenerative stimuli as well, including neurotoxic effects of corticosterone, oxidative stress, ischemia and amyloid-beta protein toxicity (Bologa et al., 1987; Kimonides et al., 1999; Bastianetto et al., 1999; Cardounel et al., 1999; Lapchak et al., 2000; Kaasik et al., 2001; Li et al., 2001; Tomas-Camardiel et al., 2002). Furthermore, DHEA displays memory-enhancing properties (Flood et al., 1992; Vallée et al., 2001) and increases adult neurogenesis in the hippocampus of rodents (Karishma and Herbert, 2002).

Pregnenolone and DHEA may exert their neuroprotective actions by several mechanisms. These may include antioxidative effects (Aragno et al., 2000), the rapid modulation of $\mathrm{GABA}_{\mathrm{A}}$, NMDA and sigma 1 receptors (Wu et al., 1991; Irwin et al., 1992; Majewska, 1992; Bergeron et al., 1996; Maurice et al., 2001), the down-regulation of glucocorticoid receptors (Cardounel et al., 1999), the regulation of protein kinase C signaling (Racchi et al., 2001) or the modulation of reactive astroglia and reactive microglia (Garcia-Estrada et al., 1999; Wang et al., 2001). Furthermore, pregnenolone is able to bind to microtubule-associated protein 2 and to stimulate microtubule assembly (Murakami et al., 2000; Plassart-Schiess and Baulieu, 2001), and therefore may exert effects on the neuronal cytoskeleton.

In addition, neuroprotective effects of pregnenolone and DHEA may be in part mediated by their conversion to testosterone and its consecutive aromatization to estradiol. To determine whether the conversion of pregnenolone and DHEA 
into estradiol is involved in the mechanism of neuroprotection of these steroids, castrated male rats were implanted with osmotic minipumps filled with the aromatase inhibitor fadrozole (Veiga et al., 2003). The administration of fadrozole prevented the neuroprotective effects of pregnenolone and DHEA against kainic acid. The effect of fadrozole was observed using high doses $(100 \mathrm{mg} / \mathrm{kg}$ ) of the steroids (Veiga et al., 2003). This finding suggests that estradiol formation by aromatase may mediate neuroprotective effects of pregnenolone and DHEA against excitotoxic-induced neuronal death in the hippocampus of adult male rats. Therefore, the aromatization of steroid precursors to estradiol may be part of an endogenous mechanism activated in the brain tissue to cope with neurodegeneration. This conclusion does not exclude alternative or complementary mechanisms for the neuroprotective effects of pregnenolone and DHEA, including the formation of 7-hydroxylated metabolites of DHEA (Jellinck et al., 2001).

\section{Is the brain or the periphery the source of substrates for brain aromatase?}

A question that is still unsolved is whether the nervous tissue may be a source of substrates for brain aromatase. Pregnenolone is synthetized in the central nervous system from cholesterol (Baulieu et al., 2001; Kimoto et al., 2001). Furthermore, glial cells, at least in vitro, may convert pregnenolone to DHEA and may then metabolize DHEA to testosterone (Zwain and Yen, 1999a,b). There is also evidence that the brain is able to form testosterone in vivo (Stoffel-Wagner et al., 1999; Stoffel-Wagner, 2001) and that neural injury enhances local brain steroidogenesis (di Michele et al., 2000; Lang, 2002; Sierra et al., 2003b). However, it is still unknown whether local formation of testosterone in the brain is of a significant amount to be relevant for neuroprotection. Furthermore, evidence for conversion in the brain of androgen precursors, such as pregnenolone or DHEA, to testosterone is still incomplete. Data obtained in vitro (Zwain and Yen, 1999a,b; Jellinck et al., 2001) cannot be directly extrapolated to the real situation in vivo, since culture conditions can produce spurious upregulation of steroidogenic enzymes. A complete mapping of steroidogenic enzymes in the central nervous system, under normal and pathological conditions, is still lacking.

Further studies should examine the neuroprotective role of aromatase substrates formed directly in the brain. So far, studies that have shown that aromatase is neuroprotective have been performed on males with intact gonads or in castrated males that have received testosterone replacement therapy or have been treated with testosterone precursors, such as pregnenolone and DHEA. Therefore, these animals have plasmatic sources of substrates for aromatase and not much can be inferred from these studies on the role of substrates formed locally in the brain. Furthermore, it is clear that testicular secretions are important for neuroprotec- tion, since castration increases vulnerability to neurotoxins (Azcoitia et al., 1999a, 2001). Ovarian hormones are also important for neuroprotection in females, since vulnerability to neurotoxins is increased by ovariectomy and is affected by the fluctuation of ovarian hormones during the estrous cycle (Azcoitia et al., 1999a). Whether, in addition to peripheral estrogens, local estradiol formation in the brain plays a neuroprotective role in females is unknown. It should be noted, however, that aromatase expression is induced in the injured brain in both sexes (Garcia-Segura et al., 1999b), suggesting that brain aromatase may also play some neuroprotective or reparative role in females.

\section{Therapeutic perspectives: neuroprotection and brain aging}

The studies reviewed in this paper suggest that the endogenous response of neural tissue to cope with neurodegenerative insults may include the induction of aromatase and the consecutive increase in the local production of estradiol. Locally formed estradiol may act on estrogen receptors, which are known to mediate neuroprotection by estradiol in several experimental models in vivo (Azcoitia et al., 1999b; Sawada et al., 2000; Veliskova et al., 2000; Wilson et al., 2000; Wise et al., 2001). In addition, aromatase may also promote neuroprotection by increasing local estradiol concentration to levels compatible with the antioxidant neuroprotective effects of the molecule (Behl and Holsboer, 1999). Since aromatase is expressed in the adult human brain, including the hippocampus (Sasano et al., 1998; Stoffel-Wagner et al., 1999; Stoffel-Wagner, 2001), this enzyme may represent a new molecular target for the therapy or prevention of neurodegenerative diseases, such as Parkinson's and Alzheimer's diseases and other aging-associated brain neurodegenerative disorders. In this regard, it is important to note that estrogen is decreased in the cerebrospinal fluid of women with aging (Murakami et al., 1999), probably reflecting a decrease in local cerebral levels of the hormone. Furthermore, estrogen is decreased both in plasma and the cerebrospinal fluid of women with Alzheimer's disease (Manly et al., 2000; Schonknecht et al., 2001), suggesting that aromatase activity or expression may be decreased in these patients.

The role of brain aromatase in neuroprotection calls for the development of new therapeutic strategies aimed at the upregulation of the enzyme in the brain without affecting its expression in other tissues. Considering the possible health risks of HRT, the regulation of local brain estradiol synthesis may offer an interesting therapeutic alternative for neuroprotection. Since the expression of the human aromatase gene, cyp19, in the various tissues is regulated by the use of tissue-specific promoters, that are regulated by different transcription factors and signaling pathways (Simpson and Davis, 2001; Kamat et al., 2002), it is possible to envisage the development of selective aromatase modulators, specific for brain tissue. Further studies are necessary to determine how 
aromatase expression is regulated in the brain and whether brain aromatase activity or expression is affected with aging, or under neurodegenerative conditions, in humans.

\section{Note added in proof}

A recent study has shown that aromatase contributes to ischemic neuroprotection in female mice (McCullough et al., 2003).

\section{Acknowledgements}

This study has been supported by grants from the Commission of the European Communities, specific RTD programme "Quality of Life and Management of Living Resources", QLK6-CT-2000-00179 and from Ministerio de Ciencia y Tecnología, Spain, SAF 2002-00652.

\section{References}

Ahlbom, E., Prins, G.S., Ceccatelli, S., 2001. Testosterone protects cerebellar granule cells from oxidative stress-induced cell death through a receptor mediated mechanism. Brain Res. 892, 255-262.

Aragno, M., Mastrocola, R., Brignardello, E., Catalano, M., Robino, G., Manti, R., Parola, M., Danni, O., Boccuzzi, G., 2000. Dehydroepiandrosterone modulates nuclear factor-kappaB activation in hippocampus of diabetic rats. Diabetes 49, 1924-1931.

Azcoitia, I., Fernandez-Galaz, M.C., Sierra, A., Garcia-Segura, L.M., 1999a. Gonadal hormones affect neural vulnerability to excitoxininduced degeneration. J. Neurocytol. 28, 699-710.

Azcoitia, I., Sierra, A., Garcia-Segura, L.M., 1999b. Neuroprotective effects of estradiol in the adult rat hippocampus: interaction with insulin-like growth factor-I signalling. J. Neurosci. Res. 58, 815-822.

Azcoitia, I., Sierra, A., Veiga, S., Honda, S., Harada, N., Garcia-Segura, L.M., 2001. Brain aromatase is neuroprotective. J. Neurobiol. 47, 318329.

Azcoitia, I., DonCarlos, L.L., Garcia-Segura, L.M., 2003a. Are gonadal steroid hormones involved in disorders of brain aging? Aging Cell 2, 31-37.

Azcoitia, I., Sierra, A., Veiga, S., Garcia-Segura, L.M., 2003b. Aromatase expression by reactive astroglia is neuroprotective. Ann. N. Y. Acad. Sci., in press.

Baetens, D., Garcia-Segura, L.M., Perrelet, A., 1982. Effects of climbing fiber destruction on large dendrite spines of Purkinje cells. Exp. Brain Res. 48, 256-262.

Balthazart, J., Ball, G.F., 1998. New insights into the regulation and function of brain estrogen synthase (aromatase). Trends Neurosci. 21, 243-249.

Balthazart, J., Foidart, A., Surlemont, C., Harada, N., 1991. Distribution of aromatase-immunoreactive cells in the mouse forebrain. Cell Tiss. Res. 263, 71-79.

Bastianetto, S., Ramassamy, C., Poirier, J., Quirion, R., 1999. Dehydroepiandrosterone (DHEA) protects hippocampal cells from oxidative stress-induced damage. Mol. Brain Res. 66, 35-41.

Baulieu, E.E., Robel, P., Schumacher, M., 2001. Neurosteroids: beginning of the story. Int. Rev. Neurobiol. 46, 1-32.

Behl, C., Holsboer, F., 1999. The female sex hormone oestrogen as a neuroprotectant. Trends Pharmacol. Sci. 20, 441-444.

Bergeron, R., de Montigny, C., Debonnel, G., 1996. Potentiation of neuronal NMDA response induced by dehydroepiandrosterone and its suppression by progesterone: effects mediated via $\sigma$ receptors. J. Neurosci. 16, 1193-1202.
Berman, F.W., Murray, T.F., 1997. Domoic acid neurotoxicity in cultured cerebellar granule neurons is mediated predominantly by NMDA receptors that are activated as a consequence of excitatory amino acid release. J. Neurochem. 69, 693-703.

Bologa, L., Sharma, J., Roberts, E., 1987. Dehydroepiandrosterone and its sulfated derivative reduce neuronal death and enhance astrocytic differentiation in brain cell cultures. J. Neurosci. Res. 17, 225-234.

Bonsall, R.W., Clancy, A.N., Michael, R.P., 1992. Effects of the non-steroidal aromatase inhibitor, Fadrozole, on sexual behavior in male rats. Horm. Behav. 26, 240-254.

Buckmaster, P.S., Dudek, F.E., 1997. Neuron loss, granule cell axon reorganization, and functional changes in the dentate gyrus of epileptic kainate-treated rats. J. Comp. Neurol. 385, 385-404.

Cardounel, A., Regelson, W., Kalimi, M., 1999. Dehydroepiandrosterone protects hippocampal neurons against neurotoxin-induced cell death: mechanism of action. Proc. Soc. Exp. Biol. Med. 222, 145-149.

Chowen, J.A., Azcoitia, I., Cardona-Gomez, G.P., Garcia-Segura, L.M., 2000. Sex steroids and the brain: lessons from animal studies. J. Pediatr. Endocrinol. Metab. 13, 1045-1066.

Clancy, A.N., Zumpe, D., Michael, R.P., 1995. Intracerebral infusion of an aromatase inhibitor, sexual behavior and brain estrogen receptor-like immunoreactivity in intact male rats. Neuroendocrinology 61, 98-111.

Costa, M.M., Reus, V.I., Wolkowitz, O.M., Manfredi, F., Lieberman, M., 1999. Estrogen replacement therapy and cognitive decline in memory-impaired post-menopausal women. Biol. Psychiatry 46, 182188.

Darnaudery, M., Pallares, M., Piazza, P., Le Moal, M., Mayo, W., 2002. The neurosteroid pregnenolone sulfate infused into the medial septum nucleus increases hippocampal acetylcholine and spatial memory in rats. Brain Res. 951, 237-242.

di Michele, F., Lekieffre, D., Pasini, A., Bernardi, G., Benavides, J., Romeo, E., 2000. Increased neurosteroids synthesis after brain and spinal cord injury in rats. Neurosci. Lett. 284, 65-68.

Fernandez, A.M., Planas, B., Torres-Aleman, I., 1999. Neuroprotective actions of peripherally administered insulin-like growth factor I in the injured olivo-cerebellar pathway. Eur. J. Neurosci. 11, 2019-2030.

Fillit, H., 1994. Estrogens in the pathogenesis and treatment of Alzheimer's disease in postmenopausal women. Ann. N. Y. Acad. Sci. 743, 233-238.

Fillit, H.M., 2002. The role of hormone replacement therapy in the prevention of Alzheimer disease. Arch. Intern. Med. 162, 1934-1942.

Flood, J.F., Morley, J.E., Roberts, E., 1992. Memory-enhancing effects in male mice of pregnenolone and steroids metabolically derived from it. Proc. Natl. Acad. Sci. U.S.A. 89, 1567-1571.

Foidart, A., Harada, N., Balthazart, J., 1995. Aromatase-immunoreactive cells are present in mouse brain areas that are known to express high levels of aromatase activity. Cell Tissue Res. 280, 561-574.

Forlano, P.M., Deitcher, D.L., Myers, D.A., Bass, A.H., 2001. Anatomical distribution and cellular basis for high levels of aromatase activity in the brain of teleost fish: aromatase enzyme and mRNA expression identify glia as source. J. Neurosci. 21, 8943-8955.

Frye, C.A., McCormick, C.M., 2000. Androgens are neuroprotective in the dentate gyrus of adrenalectomized female rats. Stress 3, 185-194.

Garcia-Estrada, J., Luquin, S., Fernandez, A.M., Garcia-Segura, L.M., 1999. Dehydroepiandrosterone, pregnenolone and sex steroids down-regulate reactive astroglia in the male rat brain after a penetrating brain injury. Int. J. Dev. Neurosci. 17, 145-151.

Garcia-Segura, L.M., Naftolin, F., Hutchison, J.B., Azcoitia, I., Chowen, J.A., 1999a. Role of astroglia in estrogen regulation of synaptic plasticity and brain repair. J. Neurobiol. 40, 574-584.

Garcia-Segura, L.M., Wozniak, A., Azcoitia, I., Rodriguez, J.R., Hutchison, R.E., Hutchison, J.B., 1999b. Aromatase expression by astrocytes after brain injury: implications for local estrogen formation in brain repair. Neuroscience $89,567-578$.

Garcia-Segura, L.M., Azcoitia, I., DonCarlos, L.L., 2001. Neuroprotection by estradiol. Prog. Neurobiol. 63, 29-60. 
Gelinas, D., Callard, G.V., 1997. Immunolocalization of aromataseand androgen receptor-positive neurons in the goldfish brain. Gen. Comp. Endocrinol. 106, 155-168.

Gouras, G.K., Xu, H., Gross, R.S., Greenfield, J.P., Hai, B., Wang, R., Greengard, P., 2000. Testosterone reduces neuronal secretion of Alzheimer's beta-amyloid peptides. Proc. Natl. Acad. Sci. U.S.A. 97, $1202-1205$.

Green, P.S., Simpkins, J.W., 2000. Neuroprotective effects of estrogens: potential mechanisms of action. Int. J. Dev. Neurosci. 18, 347-358.

Gursoy, E., Cardounel, A., Kalimi, M., 2001. Pregnenolone protects mouse hippocampal (HT-22) cells against glutamate and amyloid beta protein toxicity. Neurochem. Res. 26, 15-21.

Hammond, J., Le, Q., Goodyer, C., Gelfand, M., Trifiro, M., LeBlanc, A., 2001. Testosterone-mediated neuroprotection through the androgen receptor in human primary neurons. J. Neurochem. 77, 1319-1326.

Hogervorst, E., Williams, J., Budge, M., Riedel, W., Jolles, J., 2000. The nature of the effect of female gonadal hormone replacement therapy on cognitive function in post-menopausal women: a meta-analysis. Neuroscience 101, 485-512.

Hutchison, J.B., 1991. Hormonal control of behaviour: steroid action in the brain. Curr. Opin. Neurobiol. 1, 562-570.

Irwin, R.P., Maragakis, N.J., Rogawski, M.A., Purdy, R.H., Farb, D.H., Paul, S.M., 1992. Pregnenolone sulphate augments NMDA receptor mediated increases in intracellular $\mathrm{Ca}^{2+}$ in cultured rat hippocampal neurons. Neurosci. Lett. 141, 30-34.

Jakab, R.L., Horvath, T.L., Leranth, C., Harada, N., Naftolin, F., 1993. Aromatase immunoreactivity in the rat brain: gonadectomy-sensitive hypothalamic neurons and an unresponsive "limbic ring" of the lateral septum-bed nucleus-amygdala complex. J. Steroid Biochem. Mol. Biol. 44, 481-498.

Jakab, R.L., Harada, N., Naftolin, F., 1994. Aromatase (estrogen synthetase)-immunoreactive neurons in the rat septal area. A light and electron microscopic study. Brain Res. 664, 85-93.

Jellinck, P.H., Lee, S.J., McEwen, B.S., 2001. Metabolism of dehydroepiandrosterone by rat hippocampal cells in culture: possible role of aromatization and 7-hydroxylation in neuroprotection. J. Steroid Biochem. Mol. Biol. 78, 313-317.

Jones, K.J., 1994. Androgenic enhancement of motor neuron regeneration. Ann. N. Y. Acad. Sci. 743, 141-161.

Kaasik, A., Kalda, A., Jaako, K., Zharkovsky, A., 2001. Dehydroepiandrosterone sulphate prevents oxygen-glucose deprivation-induced injury in cerebellar granule cell culture. Neuroscience 102, 427-432.

Kamat, A., Hinshelwood, M.M., Murry, B.A., Mendelson, C.R., 2002. Mechanisms in tissue-specific regulation of estrogen biosynthesis in humans. Trends Endocrinol. Metab. 13, 122-128.

Karishma, K.K., Herbert, J., 2002. Dehydroepiandrosterone (DHEA) stimulates neurogenesis in the hippocampus of the rat, promotes survival of newly formed neurons and prevents corticosterone-induced suppression. Eur. J. Neurosci. 16, 445-453.

Kimonides, V.G., Khatibi, N.H., Svendsen, C.N., Sofroniew, M.V., Herbert, J., 1998. Dehydroepiandrosterone (DHEA) and DHEA-sulfate (DHEAS) protect hippocampal neurons against excitatory amino acid-induced neurotoxicity. Proc. Natl. Acad. Sci. U.S.A. 95, 18521857.

Kimonides, V.G., Spillantini, M.G., Sofroniew, M.V., Fawcett, J.W., Herbert, J., 1999. Dehydroepiandrosterone antagonizes the neurotoxic effects of corticosterone and translocation of stress-activated protein kinase 3 in hippocampal primary cultures. Neuroscience 89, 429-436.

Kimoto, T., Tsurugizawa, T., Ohta, Y., Makino, J., Tamura, H., Hojo, Y., Takata, N., Kawato, S., 2001. Neurosteroid synthesis by cytochrome $\mathrm{P} 450$-containing systems localized in the rat brain hippocampal neurons: $N$-methyl-D-aspartate and calcium-dependent synthesis. Endocrinology 142, 3578-3589.

Lang, S., 2002. The role of peripheral benzodiazepine receptors (PBRs) in CNS pathophysiology. Curr. Med. Chem. 9, 1411-1415.

Lapchak, P.A., Chapman, D.F., Nunez, S.Y., Zivin, J.A., 2000. Dehydroepiandrosterone sulfate is neuroprotective in a reversible spinal cord ischemia model: possible involvement of $\operatorname{GABA}(\mathrm{A})$ receptors. Stroke 31, 1953-1956.

Lee, S.J., McEwen, B.S., 2001. Neurotrophic and neuroprotective actions of estrogens and their therapeutic implications. Annu. Rev. Pharmacol. Toxicol. 41, 569-591.

Lephart, E.D., 1996. A review of brain aromatase cytochrome P450. Brain Res. Rev. 22, 1-26.

Li, H., Klein, G., Sun, P., Buchan, A.M., 2001. Dehydroepiandrosterone (DHEA) reduces neuronal injury in a rat model of global cerebral ischemia. Brain Res. 888, 263-266.

MacLusky, N.J., Naftolin, F., 1981. Sexual differentiation of the central nervous system. Science 211, 1294-1302.

Majewska, M.D., 1992. Neurosteroids: endogenous bimodal modulators of the GABAA receptor. Mechanism of action and physiological significance. Prog. Neurobiol. 38, 379-395.

Manly, J.J., Merchant, C.A., Jacobs, D.M., Small, S.A., Bell, K., Ferin, M., Mayeux, R., 2000. Endogenous estrogen levels and Alzheimer's disease among postmenopausal women. Neurology 54, 833-837.

Maurice, T., Urani, A., Phan, V.L., Romieu, P., 2001. The interaction between neuroactive steroids and the sigmal receptor function: behavioral consequences and therapeutic opportunities. Brain Res. Rev. 37, 116-132.

Mayo, W., Le Moal, M., Abrous, D.N., 2001. Pregnenolone sulfate and aging of cognitive functions: behavioral, neurochemical, and morphological investigations. Horm. Behav. 40, 215-217.

McCullough, L.D., Blizzard, K., Simpson, E.R., Oz, O.K., Hurn, P.D., 2003. Aromatase cytochrome P450 and extragonadal estrogen play a role in ischemic neuroprotection. J. Neurosci. 23, 8701-8705.

Menuet, A., Anglade, I., Le Guevel, R., Pellegrini, E., Pakdel, F., Kah, O., 2003. Distribution of aromatase mRNA and protein in the brain and pituitary of female rainbow trout: comparison with estrogen receptor alpha. J. Comp. Neurol. 462, 180-193.

Mullen, R.J., Buck, C.R., Smith, A.M., 1992. NeuN, a neuronal specific nuclear protein in vertebrates. Development 116, 201-211.

Murakami, K., Nakagawa, T., Shozu, M., Uchide, K., Koike, K., Inoue, M., 1999. Changes with aging of steroidal levels in the cerebrospinal fluid of women. Maturitas 33, 71-80.

Murakami, K., Fellous, A., Baulieu, E.E., Robel, P., 2000. Pregnenolone binds to microtubule-associated protein 2 and stimulates microtubule assembly. Proc. Natl. Acad. Sci. U.S.A. 97, 3579-3584.

Naessen, T., Lindmark, B., Larsen, H.C., 1997. Better postural balance in elderly women receiving estrogens. Am. J. Obstet. Gynecol. 177, 412-416.

Naftolin, F., 1994. Brain aromatization of androgens. J. Reprod. Med. 39, 257-261.

Naftolin, F., Ryan, K.J., Petro, Z., 1971. Aromatization of androstenedione by the diencephalon. J. Clin. Endocrinol. Metab. 33, 368-370.

Negri-Cesi, P., Melcangi, R.C., Celotti, F., Martini, L., 1992. Aromatase activity in cultured brain cells: difference between neurons and glia. Brain Res. 589, 327-332.

Nijjar, M.S., Nijjar, S.S., 2000. Domoic acid-induced neurodegeneration resulting in memory loss is mediated by $\mathrm{Ca}^{2+}$ overload and inhibition of $\mathrm{Ca}^{2+}+$ calmodulin-stimulated adenylate cyclase in rat brain. Int. J. Mol. Med. 6, 377-389.

Paganini-Hill, A., 1995. Estrogen replacement therapy and stroke. Prog. Cardiovasc. Dis. 38, 223-242.

Paganini-Hill, A., Henderson, V.W., 1996. Estrogen replacement therapy and risk of Alzheimer disease. Arch. Intern. Med. 156, 2213-2217.

Papasozomenos, S.C., 1997. The heat shock-induced hyperphosphorylation of tau is estrogen-independent and prevented by androgens: implications for Alzheimer disease. Proc. Natl. Acad. Sci. U.S.A. 94, 6612-6617.

Perez, J., Kelly, D.B., 1996. Trophic effects of androgen receptor expression and the survival of laryngeal motor neurons after axotomy. J. Neurosci. 16, 6625-6633.

Peterson, R.S., Saldanha, C.J., Schlinger, B.A., 2001. Rapid upregulation of aromatase mRNA and protein following neural injury in the zebra finch (Taeniopygia guttata). J. Neuroendocrinol. 13, 317-323. 
Pike, C.J., 2001. Testosterone attenuates beta-amyloid toxicity in cultured hippocampal neurons. Brain Res. 919, 160-165.

Plassart-Schiess, E., Baulieu, E.E., 2001. Neurosteroids: recent findings. Brain Res. Rev. 37, 133-140.

Raber, J., Bongers, G., LeFevour, A., Buttini, M., Mucke, L., 2002. Androgens protect against apolipoprotein E4-induced cognitive deficits. J. Neurosci. 22, 5204-5209.

Racchi, M., Govoni, S., Solerte, S.B., Galli, C.L., Corsini, E., 2001. Dehydroepiandrosterone and the relationship with aging and memory: a possible link with protein kinase $\mathrm{C}$ functional machinery. Brain Res. Rev. 37, 287-293.

Randell, K.M., Honkanen, R.J., Komulainen, M.H., Tuppurainen, M.T., Kroger, H., Saarikoski, S., 2001. Hormone replacement therapy and risk of falling in early postmenopausal women-a population-based study. Clin. Endocrinol. (Oxford) 54, 769-774.

Rasika, S., Alvarez-Buylla, A., Nottebohm, F., 1999. BDNF mediates the effects of testosterone on the survival of new neurons in an adult brain. Neuron 22, 53-62.

Resnick, S.M., Maki, P.M., 2001. Effects of hormone replacement therapy on cognitive and brain aging. Ann. N. Y. Acad. Sci. 949, 203-214.

Sasano, H., Takashashi, K., Satoh, F., Nagura, H., Harada, N., 1998. Aromatase in the human central nervous system. Clin. Endocrinol. (Oxford) 48, 325-329.

Saunders-Pullman, R., Gordon-Elliott, J., Parides, M., Fahn, S., Saunders, H.R., Bressman, S., 1999. The effect of estrogen replacement on early Parkinson's disease. Neurology 52, 1417-1421.

Sawada, M., Alkayed, N.J., Goto, S., Crain, B.J., Traystman, R.J., Shaivitz, A., Nelson, R.J., Hurn, P.D., 2000. Estrogen receptor antagonist ICI 182,780 exacerbates ischemic injury in female mouse. J. Cereb. Blood Flow Metab. 20, 112-118.

Schlinger, B.A., Amur-Umarjee, S., Shen, P., Campagnoni, A.T., Arnold, A.P., 1994. Neuronal and non-neuronal aromatase in primary cultures of developing zebra finch telencephalon. J. Neurosci. 14, 7541-7552.

Schlinger, B.A., Amur-Umarjee, S., Campagnoni, A.T., Arnold, A.P., 1995. 5 beta-reducatse and other androgen-metabolizing enzymes in primary cultures of developing zebra finch telencephalon. J. Neuroendocrinol. 7, 187-192.

Schonknecht, P., Pantel, J., Klinga, K., Jensen, M., Hartmann, T., Salbach, B., Schroder, J., 2001. Reduced cerebrospinal fluid estradiol levels are associated with increased beta-amyloid levels in female patients with Alzheimer's disease. Neurosci. Lett. 307, 122-124.

Schmued, L.C., Albertson, C., Slikker Jr., W., 1997. Fluoro-Jade: a novel fluorochrome for the sensitive and reliable histochemical localization of neuronal degeneration. Brain Res. 751, 37-46.

Shaywitz, B.A., Shaywitz, S.E., 2000. Estrogen and Alzheimer disease: plausible theory, negative clinical trial. J. Am. Med. Assoc. 283, 10551056.

Sherwin, B.B., 1999. Can estrogen keep you smart? Evidence from clinical studies. J. Psychiatry Neurosci. 24, 315-321.

Shughrue, P.J., Lane, M.V., Merchenthaler, I., 1997. Comparative distribution of estrogen receptor-alpha and -beta mRNA in the rat central nervous system. J. Comp. Neurol. 388, 507-525.

Sierra, A., Azcoitia, I., Garcia-Segura, L.M., 2003a. Endogenous estrogen formation is neuroprotective in a model of cerebellar ataxia. Endocrine $21,43-52$.

Sierra, A., Lavaque, E., Perez-Martin, M., Azcoitia, I., Hales, D.B., Garcia-Segura, L.M., 2003b. Steroidogenic acute regulatory protein in the rat brain: cellular distribution, developmental regulation and overexpression after injury. Eur. J. Neurosci. 18, 1458-1467.

Simpson, E.R., Davis, S.R., 2001. Minireview: aromatase and the regulation of estrogen biosynthesis-some new perspectives. Endocrinology 142, 4589-4594.

Smith, S.S., 1998. Estrous hormones enhance coupled, rhythmic olivary discharge in correlation with facilitated limb stepping. Neuroscience $82,83-95$.
Stoffel-Wagner, B., 2001. Neurosteroid metabolism in the human brain. Eur. J. Endocrinol. 145, 669-679.

Stoffel-Wagner, B., Watzka, M., Schramm, J., Bidlingmaier, F., Klingmuller, D., 1999. Expression of CYP19 (aromatase) mRNA in different areas of the human brain. J. Steroid Biochem. Mol. Biol. 70, 237-241.

Strain, S.M., Tasker, R.A., 1991. Hippocampal damage produced by systemic injections of domoic acid in mice. Neuroscience 44, 343-352.

Tomas-Camardiel, M., Sanchez-Hidalgo, M.C., Sanchez del Pino, M.J., Navarro, A., Machado, A., Cano, J., 2002. Comparative study of the neuroprotective effect of dehydroepiandrosterone and 17beta-estradiol against 1-methyl-4-phenylpyridium toxicity on rat striatum. Neuroscience 109, 569-584.

Tsang, K.L., Ho, S.L., Lo, S.K., 2000. Estrogen improves motor disability in parkinsonian postmenopausal women with motor fluctuations. Neurology 54, 2292-2298.

Vagell, M.E., McGinnis, M.Y., 1997. The role of aromatization in the restoration of male rat reproductive behavior. J. Neuroendocrinol. 9, $415-421$.

Vallée, M., Mayo, W., Darnaudéry, M., Corpéchot, C., Young, J., Koehl, M., Le Moal, M., Baulieu, E.E., Robel, P., Simon, H., 1997. Neurosteroids: deficient cognitive performance in aged rats depends on low pregnenolone sulfate levels in the hippocampus. Proc. Natl. Acad. Sci. U.S.A. 94, 14865-14870.

Vallée, M., Mayo, W., Le Moal, M., 2001. Role of pregnenolone, dehydroepiandrosterone and their sulfate esters on learning and memory in cognitive aging. Brain Res. Rev. 37, 301-312.

Veiga, S., Garcia-Segura, L.M., Azcoitia, I., 2003. Neuroprotection by the steroids pregnenolone and dehydroepiandrosterone is mediated by the enzyme aromatase. J. Neurobiol. 56, 398-406.

Veliskova, J., Velisek, L., Galanopoulou, A.S., Sperber, E.F., 2000. Neuroprotective effects of estrogens on hippocampal cells in adult female rats after status epilepticus. Epilepsia 41 (Suppl. 6), S30-35.

Wang, M.J., Huang, H.M., Chen, H.L., Kuo, J.S., Jeng, K.C., 2001. Dehydroepiandrosterone inhibits lipopolysaccharide-induced nitric oxide production in BV-2 microglia. J. Neurochem. 77, 830-838.

Wilson, M.E., Dubal, D.B., Wise, P.M., 2000. Estradiol protects against injury-induced cell death in cortical explant cultures: a role for estrogen receptors. Brain Res. 873, 235-242.

Wise, P.M., 2003. Estrogens: protective or risk factors in brain function? Prog. Neurobiol. 69, 181-191.

Wise, P.M., Dubal, D.B., Wilson, M.E., Rau, S.W., Liu, Y., 2001. Estrogens: trophic and protective factors in the adult brain. Front. Neuroendocrinol. 22, 33-66.

Wolf, O.T., Kudielka, B.M., Hellhammer, D.H., Torber, S., McEwen, B.S., Kirschbaum, C., 1999. Two weeks of transdermal estradiol treatment in postmenopausal elderly women and its effect on memory and mood: verbal memory changes are associated with the treatment induced estradiol levels. Psychoneuroendocrinology 24, 727-741.

Wu, F.S., Gibbs, T.T., Farb, D.H., 1991. Pregnenolone sulphate: a positive allosteric modulator at the $N$-methyl-D-aspartate receptor. Mol. Pharmacol. 40, 333-336.

Yaffe, K., Sawaya, G., Lieberburg, I., Grady, D., 1998. Estrogen therapy in postmenopausal women: effects on cognitive function and dementia. J. Am. Med. Assoc. 279, 688-695.

Yu, W.H., 1982. Effect of testosterone on the regeneration of the hypoglossal nerve in rats. Exp. Neurol. 77, 129-141.

Zwain, I.H., Yen, S.S.C., 1999a. Dehydroepiandrosterone: biosynthesis and metabolism in the brain. Endocrinology 140, 880-887.

Zwain, I.H., Yen, S.S.C., 1999b. Neurosteroidogenesis in astrocytes, oligodendrocytes, and neurons of cerebral cortex of rat brain. Endocrinology 140, 3843-3852.

Zwain, I.H., Yen, S.S.C., Cheng, C.Y., 1997. Astrocytes cultured in vitro produce estradiol-17 $\beta$ and express aromatase cytochrome P-450 (P-450 AROM) mRNA. Biochim. Biophys. Acta 1334, 338-348. 